\title{
Diez copias decimonónicas de una salva portuguesa del siglo Xvi en Austria, España y Portugal: en torno a su procedencia y autoría
}

\author{
Ana Pérez Varela \\ Universidade de Santiago de \\ Compostela
}

RESUMEN:

Este estudio pretende ser el análisis de una serie de piezas de finales del siglo XIX que copian una bella salva lisboeta del siglo XVI conservada en el Kunsthistorisches Museum de Viena, de acuerdo con la mentalidad romántica e historicista de la platería decimonónica. Hemos hallado copias e imitaciones de la pieza relacionadas con el artista Ricardo Martínez Costoya, platero oficial de la catedral de Santiago de Compostela entre 1886 y 1924; y con Karl Haas, quien dirigió desde 1866 el atelier de galvanoplastia de la Escuela de Artes Aplicadas de Viena. En este estudio trataremos de determinar la curiosa iconografía de la salva; y sobre todo, reflexionar sobre las atribuciones a Martínez basándonos en nuestro conocimiento sobre el artista, y su diferencia con las que nosotros atribuimos a Haas.

\section{PALABRAS CLAVE:}

Platería, salva, siglo XVI, siglo XIX, iconografía

\section{ABSTRACT:}

This paper aims to be the analysis of a series of pieces made in the late nineteenth century that copy a beautiful Portuguese plat from the sixteenth century placed in the Kunsthistorisches Museum in Vienna, according to the romantic and historicist set of mind of the silversmithing in the nineteenth century. We have found copies and imitations of the piece related to the artist Ricardo Martínez Costoya, official silversmith of the cathedral of Santiago de Compostela between 1886 and 1924; and with Karl Haas, who run the galvanoplastic atelier in the School of Applied Arts in Vienna from 1866. In this study, we will try to determine the curious iconography of the plate; and especially, we will reflect about the attributions to Martinez based on our knowledge of the artist, and the difference between the pieces we attribute to Haas.

KEYWORDS:

Silversmithing, plat, sixteenth century, nineteenth century, iconography 
1. El tipo

La pieza se enmarca en una tipología muy habitual en la platería portuguesa del siglo XVI. Un simple vistazo a las piezas civiles conservadas en territorio luso nos revela la existencia de numerosas bandejas renacentistas de este tipo ${ }^{1}$, de forma circular, siguiendo el modelo de dos o tres fajas concéntricas en torno a un asiento en forma de disco. La superficie no es plana, sino que las secciones intermedias suelen presentar una concavidad muy acusada, mientras que los centros suelen ser convexos.

Estas piezas se decoraban con historias de gusto cortesano, transparentando el interés por los ciclos caballerescos, de inspiración bélica, explicados fácilmente en el contexto de los descubrimientos y el interés por lo exótico y el imaginario de la conquista ${ }^{2}$. Tampoco faltan los episodios bíblicos o mitológicos, así como elementos decorativos fitomórficos, geométricos o procedentes del bestiario medieval.

Formalmente, estas obras eclécticas, propias del estilo manuelino, se mueven entre las características del tardogótico y el primer renacimiento. Las primeras se manifiestan especialmente en su naturaleza ornamental, en el que destaca el horror vacui traducido a toda su superficie, profusamente decorada; mientras que las segundas subyacen en aspectos epidérmicos como detalles decorativos en base a motivos a candelieri, grutescos o florones ${ }^{3}$.

Lo que hoy denominamos salvas está en relación etimológica con el proceso llevado a cabo por el trinchante para verter un poco de comida o bebida y probarla antes que el señor para certificar que no estaba envenenada, hecho denominado precisamente faze-la salva, y para el que en realidad se empleaban piezas de diversos tipos. Entre ellas se encontraban las bandejas hoy llamadas de forma común salvas, debido a una asimilación del nombre de la ac-

\footnotetext{
Nos referiremos a ellas en este estudio por el número de inventario en la base de datos "matriznet" (http:// www.matriznet.dgpc.pt), herramienta que nos permitió acercarnos a este material en un primer estadio de la investigación.

2 ANDRADE, María do Carmo Rebello de, "Artes de mesa e cerimoniais régios na corte do século XVI. Uma viagem a través de obras de arte da ourivesaria nacional", en $A$ mesa dos reis de Portugal, Círculo de Leitores, Porto, 2011, p. 134.

3 SILVA, Nuno Vassallo e, Ourivesaria Portuguesa de Aparato. Séculos XV e XVI, SCRIBE, Lisboa, 2012, pp. 85-151.
}

ción por parte de la pieza. Sin embargo, este tipo de obras fueron encargadas en numerosas ocasiones por la corona portuguesa y por las familias nobiliarias más importantes del reino, para servir tanto como ostentación personal como para intercambiar como regalo diplomático. Se trata por lo tanto, en muchos casos, de piezas de aparato, sin uso práctico o utilitario en el servicio de mesa, en un contexto de lujo cortesano protocolario, que a menudo se colocaban en aparadores como telón de fondo de las comidas 4 .

El siglo XVI significó para Portugal el apogeo de su platería, y este tipo de pieza se convirtió en una de sus mejores expresiones, conservándose un gran número de ellas con variados programas iconográficos. Contamos con espléndidas colecciones de ejemplares en el Palácio Nacional da Pena ${ }^{5}$; el Museu Nacional de Arte Antiga ${ }^{6} ;$ y muy especialmente en el Palácio Nacional da Ajuda ${ }^{7}$, muchas de ellas provenientes del vasto conjunto de platería de la monarquía portuguesa.

\footnotetext{
Para ampliar sobre su función de ostentación y la problemática de la palabra salva, véanse: CAETANO, Joaquim Oliveira, "Função, decoração e iconografia das salvas”, en Inventário do Museu Nacional de Arte Antiga. A Colecção de Ourivesaria, vol. 1: Do Românico ao Manuelino, Instituto Português de Museus, Lisboa, 1995, pp. 148-151; ANDRADE, María do Carmo Rebello de, "Artes de... opus cit., p. 134; SILVA, Nuno Vassallo e, Ourivesaria Portuguesa... opus cit., pp. 67-69 y 160; y CRESPO, Hugo Miguel, A mesa do príncipe. Jantar e cear na corte de Lisboa (1500-1700), ARPAB, Lisboa, 2018, p. 68-69.

5 Destaca la núm. PNP3526, con tondos figurados con episodios mitológicos, de clara inspiración renacentista 6 Destacan la núm. 83 Our, con alegorías de las Artes Liberales; la núm. 806, con decoraciones fantasiosas de bestias y hombres salvajes; o la núm. 1015 Our, con una carabela.

7 Los ejemplos son incontables, aunque tenemos que destacar algunos ejemplares sobresalientes: las núm. 4815, 4817 y 5167, con escenas que pueden estar en relación a la conquista de Arzila; la núm. 4812, de escenas caballerescas; la núm. 4808, con escenas de batallas navales y de caza; la núm. 5165, con la historia de San Jorge y el dragón; las núm. 4801, 4803 y 5164, con escenas veterotestamentarias; las núm. 4814 y 5157, con motivos fitomórficos mezclados con animales fantasiosos; las núm. 5158 y 5163, con una mezcla de animales, bustos y figuras no identificadas; la núm. 5161, con imágenes de los vicios y virtudes; la núm. 4813, con la entrada triunfal de Julio César; la núm. 4818, con la historia de Vespasiano; las núm. 5155 y 4810, con curiosa iconografía exótica africana; y finalmente, la núm. 4807, con escenas, al igual que
} la bandeja de Viena, de la historia de Judit. 


\section{La pieza del Kunsthistorisches Museum de} Viena

La pieza protagonista de este estudio (fig. 1) es una bella bandeja de plata en su color, con el anverso íntegramente sobredorado. Está conservada en el Kunsthistorisches Museum de Viena (núm. de inventario: KK 904), datada a mediados del siglo $\mathrm{XVI}^{8}$. No presenta marca conocida, y ostenta una medida de 50,7 centímetros de diámetro. Estructuralmente se trata de una obra dividida en tres franjas concéntricas completamente historiadas, circunscribiendo un asiento en el que observamos un escudo de armas.

En este ejemplo custodiado en Viena, el programa iconográfico de la franja externa reproduce la historia secuenciada de Judit, en la cual la heroína hebrea, ayudada por Dios, consigue engañar a Holofernes, general del rey asirio Nabucodonosor, que se encontraba cercando su ciudad, y termina cortándole la cabeza.

El tema de la historia de Judit es recurrente en este tipo de piezas en Portugal durante la época renacentista. Además de estos dos ejemplares mencionados, encontramos otros ${ }^{9}$ en la

8 La pieza ha participado en varias exposiciones internacionales: Versalles (OBERHAMMER, Vinzenz (com.), Vienne à Versailles, Musées Nationaux, París, 1964, p. 122); Lisboa (Os Descobrimentos Portugeses e a Europa do Renascimento: Ábrese a terra en sons e cores. As descobertas e op Renascimento. Formas de coincidencia e de cultura, Presidencia do Consello de Ministros, Lisboa, 1983, p. 172, pieza 132); Viena (SEIPEL, Wilfried (dir.), Szenen aus dem Buch Tobias, Kunthistorisches Museum, Viena, 2004); Mannheim (HAAG, Sabine y WIECZOREK, Alfried (et. al.), Sammeln!: Die Kunstkammer des Kaisers in Wien, Prestel, Munich-Londres-Nueva York, 2012, p. 103); y Minneapolis-Houston-Atlanta (KURZEL-RUNTSCHEINER, Mónica (ed.), Habsburg splendor. Masterpieces from Vienna's Imperial Collections at the Kunsthistorisches Museum, Museum of Fines Arts, Houston, 2015, pp. 96-97). Próximamente lo hará en Tokio (inauguración en octubre de 2019). Además, fue recogida en el propio catálogo del Kunthistorisches Museum: KRIS, Ernst, y PLANISCIG, Leo, Katalog der Sammlung für Plastik und Kunstgewerbe, Kunthistorisches Museum, Viena, 1935, pp. 55-56; en KRIS, Ernst, Goldschmiedearbeiten. Des mittelalters, der Renaissance und des Barock, Verlag Von Anton Schroll \& Co., Viena, 1932, p. 16; en HERNMARCK, Carl, The art of the European Silversmith. 14301830, 2 volúmenes, Sotheby Parke Bernet, Londres, 1977, vol. II, p. 222; y en SILVA, Nuno Vassallo e, Ourivesaria Portuguesa... opus cit., p. 222-224.

9 Tuvimos noticia de otro ejemplar en el Museo del Renacimiento del Château d'Ecouen (Francia), mencionado por Ruival Ferreira como una obra que presenta la historia de Judit y Holofernes (FERREIRA, Sofía Ruival (FERREIRA, Sofía Ruival, "Revivalismos ou falsifi-

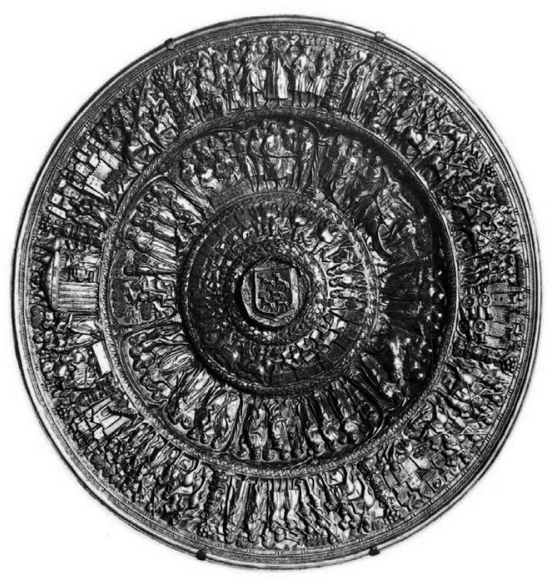

45

Fig. 1. Anónimo, Salva de Judit y Holofernes, plata sobredorada relevada, Kunsthistorisches Museum, Viena, Núm. Inv. KK 904, mediados del siglo XVI, fotografía publicada en: Vienne à Versailles, Musées Nationaux, París, 1964, p. 122.

Real Colegiata de San Isidoro de León ${ }^{10}$ con marca de Lisboa y artífice «JA»" Nacional da Ajuda ${ }^{12}$; en el Metropolitan Mu-

cações: uma questão de data”, en Actas do II Colóquio Português de Ourivesaria, Universidade Católica Editora, Porto, 2009, p. 293). Sin embargo, cuando nos pusimos en contacto con el museo para solicitar imágenes, nos informaron de que la pieza reproducida por la autora (núm. de inventario E.Cl. 20743) no se corresponde con esta iconografía, sino que ostenta una representación de las siete artes liberales en la franja intermedia, y los siete pecados capitales y las siete virtudes en la franja exterior. Queremos agradecer a mme. Julie Rohou y mme. Muriel Barbier, conservadoras del museo, por la atención recibida y su amabilidad. La obra fue recogida en SILVA, Nuno Vassallo e, Ourivesaria Portuguesa... opus cit., pp. 134-135.

10 CRUZ VALDOVINOS, José Manuel, Platería Europea en España, Fundación Central Hispano, Madrid, 1997, pp. 96-97

11 La marca de localidad es la variante L-5 de Moitinho de Almeida, datada en la primera mitad del siglo XVI (ALMEIDA, Fernando Moitinho de, Inventário de marcas de pratas portuguesas e brasileiras. Século XV a 1887, Imprensa Nacional Casa da Moeda, Lisboa, 1993, p. 75). La marca de artífice, JA, fue identificada por Cruz Valdovinos como posible de los autores João Alfonso (documentado en 1473-1507) o João Álvares el mozo (documentado en 1473-1525) (CRUZ VALDOVINOS, José Manuel, Platería Europea... opus cit., p. 96), basándose en la marca 157 del catálogo de Santos y Quilhó (SANTOS, Reynaldo dos; y QUILHÓ, Irene, $\mathrm{Ou}$ rivesaria portuguesa nas colecções particulares, Neogravura, Lisboa, 1974, p. 250). El historiador cree que es más probable que sea obra del segundo, teniendo en cuenta la cronología, que él retrasa a principios del siglo XV (CRUZ VALDOVINOS, José Manuel, Platería Europea... opus cit., p. 96), con respecto a Herráez Ortega, que dio la fecha de 1525 (HERRÁEZ ORTEGA, María Victoria, Enrique de Arfe y la orfebrería gótica en León, Universidad de León, León, 1988, pp. 189-199).

12 SILVA, Nuno Vassallo e, Ourivesaria Portuguesa... opus cit., p. 130. 
seum of Art de Nueva York ${ }^{13}$, o un ejemplar en colección particular subastado en París en $2008^{14}$.

En cuanto a la franja intermedia, su interpretación no está clara. Ruival Ferreira propuso una lectura iconográfica de la pieza relacionando las escenas de esta franja también con la historia de Judit, dando unas interpretaciones a las extrañas figuras desnudas basándose en la historia de Ajior, jefe de los amonitas, que decidió unirse a la causa hebrea y circuncidarse (Jdt. 3, 5, 6 y 14) ${ }^{15}$. Sin embargo, la dificultad de la autora de encontrar explicación a escenas como un jardín donde vemos un perro y hombres despojados de sus trajes, nos ha llevado a buscar otras lecturas.

A pesar de que Vassallo e Silva relacionó esta secuencia iconográfica con posibles episodios de la expansión misionaria, especialmente de los mártires de Marruecos ${ }^{16}$, nosotros nos hemos interesado por la lectura que propone el catálogo de Sotheby's de 2008, no de esta pieza, sino de la subastada en París a la que nos acabamos de referir, cuya secuencia iconográfica resultan muy similar (fig. 2) ${ }^{17}$.

Esta segunda obra fue datada hacia $1500^{18}$, y por lo tanto es anterior a la de Viena, ciudad en la que parece, también estuvo la subastada en París ${ }^{19}$. Asimismo, su franja externa está de-

13 SILVA, Nuno Vassallo e, Ourivesaria Portuguesa... opus cit., p. 131.

14 SOTHEBY'S, European silver, gold boxes and objects of vertu, París, 30 de octubre de 2008, lote 174, recuperado de: http://www.sothebys.com/en/auctions/ecatalogue/2008/european-silver-gold-boxes-and-objects-ofvertu-pf8013/lot.174.html [03/06/2018].

15 FERREIRA, Sofía Ruival, Salva de aparato 'Judite e Holofernes', Lisboa, 2007, recuperado de: https://archive. org/details/SalvajuditeEHolofernes [03/06/2018], sin p.

16 SILVA, Nuno Vassallo e, Ourivesaria Portuguesa... opus cit., p. 223.

17 Debemos agradecer a mr. Paulus Rainer, conservador del Kunsthistorisches Museum de Viena, por darnos a conocer esta referencia.

18 La cronología de 1500 viene apoyada por el tipo de armas y de vestimenta militar empleada por los soldados portugueses y españoles; así como los elementos de las vestimentas de los civiles. SOTHEBY'S, European silver... opus cit., sin p..

19 Anteriormente había sido subastada por Christie's en Ginebra en 1975. Luego fue comprada a Jacques Kugel, fundador de la Galería Kugel en París. El catálogo apunta a que posiblemente fuese una pieza realizada para la corte portuguesa, quizás también propiedad de Catalina de Habsburgo, esposa de João III, hijo y sucesor de Manuel I, que también pudo ser propietaria de la salva de Viena. SOTHEBY'S, European silver... opus cit., sin p.

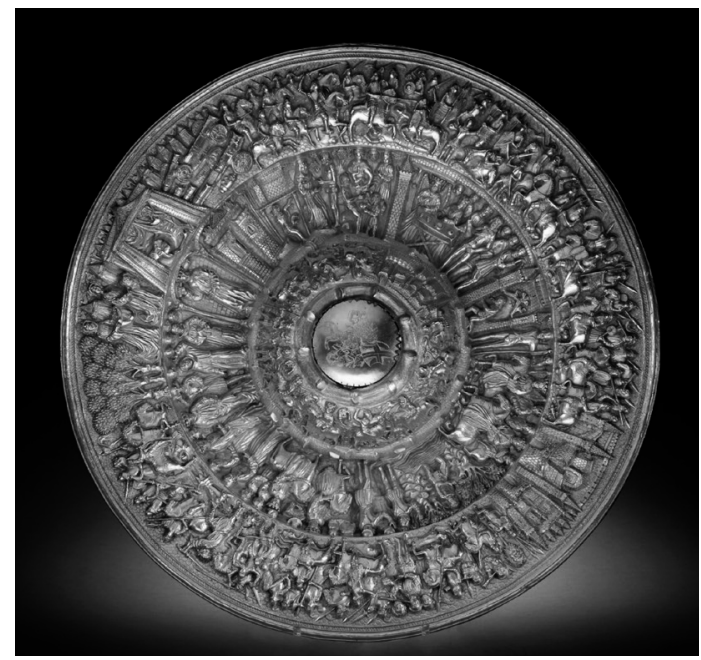

Fig. 2. Anónimo, Salva de Guy de Warwick, plata sobredorada relevada, colección particular, ca. 1500, fotografía proporcionada por Sotheby's / Art Digital Studio.

corada con la historia de Judit, mientras que la intermedia se identificó con la representación de un ciclo de la vida de Guy de Warwick ${ }^{20}$, un tema de literatura caballeresca medieval (ca. 1300) procedente de Inglaterra ${ }^{21}$. En el catálogo se aludió a la salva vienesa y se sugirió la posibilidad de que también estuviese representando este asunto. Aunque no podemos detenernos en este estudio en los detalles iconográficos, una comparación entre ambas nos muestra detalles

20 Éste cuenta la historia de un caballero que se enamora de una mujer llamada Felice, con quien se casa tras volver de su particular cruzada matando gigantes, dragones y bestias para probarle su amor. Tras la boda, avergonzado por su pasado violento, emprende una peregrinación a Tierra Santa exiliándose posteriormente a la naturaleza salvaje. Años después, se acerca a una ciudad que está siendo cercada. Un ángel conduce a su mujer y su séquito hasta las puertas de la ciudad, donde se encuentra el héroe barbado y despeinado. Finalmente, el ángel lo revela a su corte como el héroe y el salvador de la ciudad. Más tarde se retira como ermitaño y continúa viviendo en la naturaleza. Para ampliar sobre la historia, véase: RICHMOND, Velma Bourgeois, The legend of Guy of Warwick, Garland, Nueva York, 1996.

21 No resulta difícil explicar la presencia de este tema en Portugal. Se conoce una versión del valenciano Joanot Martorell que escribió durante su estancia en la corte de Enrique VI en Inglaterra en 1438-1439, titulándola "Guillem de Varoich" (Biblioteca Nacional, DL/903087), que pasó a formar parte de su célebre Tirant lo Blanc, publicada póstumamente en 1490. El escritor tradujo la leyenda de Guy de Warwick al portugués y se la dedicó a Fernando de Portugal (1433-1470), padre del rey Manuel I (1469-1521). Esta vía explica claramente la introducción de la leyenda en el país vecino y su empleo en esta salva historiada. SOTHEBY'S, European silver... opus cit., sin $\mathrm{p}$. 
suficientemente similares como para que consideremos que las dos salvas estén representando la vida de Guy de Warwick, tales como el ángel, un ermitaño desnudo -el supuesto Ajior según Ruival Ferreira-, un rey, una reina, un séquito, animales salvajes -los extraños perros- y escenas de revelación -el bautizo o la presentación del supuesto Ajior ante Judit y Holofernes-. Desgraciadamente, la historia de Guy de Warwick es un ciclo muy poco representado en el arte, por lo que tampoco podemos realizar comparaciones compositivas e iconográficas con otros soportes artísticos.

Prosiguiendo en la lectura iconográfica de la pieza que nos ocupa, la tercera faja, la más próxima al centro, está cubierta por un ejército en marcha y ciudades amuralladas. Para Ruival Ferreira representa la liberación, por parte de los ejércitos hebreos de los pueblos subyugados por Holofernes ${ }^{22}$. El catálogo de Minneapolis-Houston-Atlanta, donde fue exhibida la salva vienesa en 2015, lo relacionó, al contrario, con las conquistas del ejército asirio ${ }^{23}$. Teniendo en cuenta que no hay ningún elemento iconográfico destacable, pensamos que éste es un registro meramente decorativo que demuestra una vez más el gusto por lo caballeresco y militar que impregna estas salvas de acuerdo con sus comitentes.

Finalmente, el escudo que centra la bandeja se corresponde a las armas de los Lobo de Silveira. Según los inventarios, sabemos que esta obra estuvo en el castillo de Franzensburg (Laxenburg) hasta 1872, cuando se incorporó a las colecciones del Kunsthistorisches Museum, todavía en proceso de formación. Según el catálogo de Sotheby's anteriormente aludido, esta pieza pudo haber entrado en Viena a través de distintas vías, dadas las conexiones tan importantes entre Austria, España y Portugal en los siglos XV y XVI. El autor apuntó que pudo ser propiedad de Catalina de Habsburgo (15071578), hermana de Carlos V (1500-1558) y Fernando I (1503-1564), emperadores del Sacro Imperio Germánico. Catalina se casó con João III (1502-1557) y pasó a ser reina de Portugal en 1525, en un momento en el que sabemos que el envío de regalos y presentes entre ambas casas fue frecuente ${ }^{24}$. El catálogo relacionó el

22 FERREIRA, Sofía Ruival, Salva de... opus cit., sin p.

23 KURZEL-RUNTSCHEINER, Mónica (ed.), Habsburg splendor.. opus cit., pp. 96-97.

24 SOTHEBY'S, European ... opus cit., sin p. escudo de la obra con don Diego Lobo de Silveira, que fue gran chambelán de los reyes João II y Manuel I, este último suegro de Catalina de Habsburgo ${ }^{25}$.

Sin embargo, el catálogo de Mannheim, donde la pieza fue expuesta en 2012, señaló que las armas heráldicas de la salva de Viena son claramente posteriores a la ejecución de la pieza porque el título de los condes de Oriola no fue creado hasta $1653^{26}$. Ya el catálogo del Kunsthistorisches de 1935 había dudado de la autenticidad del asiento ${ }^{27}$. Efectivamente, debemos acercarnos con cautela a los discos centrales de cualquier salva portuguesa del siglo $\mathrm{XVI}$, ya que fue habitual que se cambiasen a posteriori para honrar a nuevos propietarios, así como es habitual que ostenten pies añadidos más $\operatorname{tarde}^{28}$. En las salvas mencionadas del Palácio Nacional da Ajuda tenemos numerosos ejemplos con discos centrales ${ }^{29}$ y pies $^{30}$ añadidos con posterioridad.

A diferencia de los ejemplos anteriormente mencionados que recogían la historia de Judith -León, Lisboa, Nueva York, y París-, y con la excepción de la del Palácio Nacional da Ajuda, que también lo hace, la bandeja del Kunsthistorisches presenta los episodios de la historia de Judith compartimentados mediante elegantes separaciones. En los de la faja exterior se realiza a base de elementos abalaustrados de raíz renacentista; mientras que en los de la faja intermedia se consigue enmarcando las escenas por una arcada en cuyas enjutas se colocan cabezas de querubines, y apoyada en columnillas helicoidales cada dos arcos, dejando los otros sin apoyo. Asimismo, en todos estos ejemplos -excepto en París- las fajas concéntricas son dos, y están separadas por anillos lisos. En Viena, sin embargo, las franjas decorativas son tres y se separan por elegantes sogueados que indican, al igual que los susodichos elementos de separación, una mayor modernidad y una

\footnotetext{
25 SOTHEBY'S, European silver opus cit., sin p.

26 HAAG, Sabine y WIECZOREK, Alfried (et. al.), Sammeln!: Die... opus cit., p. 103.

27 KRIS, Ernst, y PLANISCIG, Leo, Katalog der... opus cit, pp. 55-56.

28 SILVA, Nuno Vassallo e, Ourivesaria Portuguesa... opus cit., pp. 148-151.

29 Núms. de inventario en matriznet: 4801; 4803; 4807; 4808; 4812, 4813; 4815; 4817; 5157; $5158 ; 5161 ; 5164 ;$ y 5167.

$30 \quad$ Núms. de inventario en matriznet: 4801; 4803; 4807; 4808; 4812; 4813; 4815; 4817; 5157; 5158; y PNP3526.
} 
cronología más avanzada ${ }^{31}$. La bandeja de París también presenta tres fajas ornamentales pero no están separadas por ningún elemento más que un finísimo bocel que apenas subraya la transición. Sin embargo, el borde de ambas es idéntico, fileteado, con una fina cenefa de equis. El catálogo de Sotheby's también apunta otras características similares, como el canon alargado de las figuras, o el uso de adargas ovaladas como escudos propios de los ejércitos español y portugués ${ }^{32}$.

En este tipo de bandejas hemos observado una preferencia por dos tipos de decoraciones de raíz narrativa: las mitológicas y las bíbli$\operatorname{cas}^{33}$. Las primeras están claramente justificadas por el gusto de la época y la introducción del interés, propio del Renacimiento, por este tipo de representaciones, especialmente en contextos palaciegos y de ostentación. Por su parte, las escenas bíblicas sirven de excusa para representar escenas de batalla, y por lo tanto no están en relación a un contexto religioso, sino también a un contexto de mentalidad nobiliaria. Los comitentes de estas salvas debían estar más interesados en las andanzas caballerescas y militares que en los episodios veterotestamentarios $^{34}$. A menudo, componentes bíblicos se mezclan con elementos castrenses, navales o cinegéticos.

En el catálogo de Sotheby's se aludió a que la guerra entre el ejército hebreo y el asirio en el episodio de Judit en las piezas de París y Viena pudiesen estar representando acontecimientos portugueses contemporáneos, como la conquista de Arzila en el Norte de África (1471) ${ }^{35}$. Se han relacionado directamente algunas escenas bélicas de bandejas portuguesas con esta batalla concreta, como por ejemplo en dos salvas en

31 CRUZ VALDOVINOS, José Manuel, Platería Europea... opus cit., pp. 96-97.

32 SOTHEBY'S, European silver... opus cit., sin p.

33 Algunos de los temas iconográficos más repetidos ya han sido apuntados en la nota 7.

34 SOUSA, Ana Cristina, "Levantadas em bestiães e em silvados: o bestiário e o fantástico nas salvas historiadas dos séculos XV e XVI", comunicación en el XI Congreso de la Sociedad Española de Emblemática: El sol de Occidente. Sociedad, textos, imágenes simbólicas e interculturalidad, Santiago de Compostela 29 de noviembre-2 de diciembre de 2017, actas pendientes de publicación. Agradecemos a la autora que nos proporcionase su manuscrito para consulta.

35 SOTHEBY'S, European silver... opus cit., sin p.; y SILVA, Nuno Vassallo e, Ourivesaria Portuguesa... opus cit., p. 138. el Palácio Nacional de Ajuda ${ }^{36}$, o una en el Victoria \&t Albert que toma como excusa la representación de la Guerra de Troya para referirse a Arzila ${ }^{37}$. Según el citado catálogo, la versión de la historia de Guy de Warwick en la bandeja de París estaría eliminando al rey Aethelstan de la historia y también adaptando a los enemigos de los ingleses, los vikingos, a los homónimos de la península Ibérica, los árabes, presentando así una iconografía acorde con el gusto y las exigencias de la corte portuguesa y española ${ }^{38}$.

\section{Las reproducciones e imitaciones ${ }^{39}$ decimonónicas: de Lisboa a Viena, de Viena a Compostela}

Partiendo de la mentalidad romántica de recuperación de los estilos históricos, característica del siglo XIX, fue habitual que la platería decimonónica copiase e imitase modelos inspirados en todas las épocas artísticas. A finales de siglo es común encontrar en todo el territorio europeo piezas historicistas, especialmente de raíz neogótica, aunque también renacentista y barroca. Las salvas portuguesas fueron vistas como testimonio de un pasado de ostentación nobiliaria y a menudo caballeresca, plagadas de elementos exóticos y atrayentes como caprichosas formas vegetales y variados ejemplos del bestiario medieval, y especialmente, de escenas mitológicas, militares y de batalla ${ }^{40}$. En

36 Núms. de inventario 4815 y 5167. La segunda fue publicada en: ANDRADE, María do Carmo Rebello de, "Artes de mesa... opus cit., p. 135.

37 SILVA, Nuno Vassallo e, Ourivesaria Portuguesa... opus cit., pp. 137-139.

38 SOTHEBY'S, European silver... opus cit., sin p.

39 Cruz Valdovinos señaló la diferencia entre reproducción/copia, imitación e historicismo. La primera sería aquélla que se realiza sobre el original, normalmente mediante galvanoplastia. No lleva marcas y no pretende, en principio, pasar por pieza original. La segunda sería aquélla que imita una pieza también existente, pero no mediante un procedimiento de reproducción en serie o sobre la pieza. Normalmente, incorpora marcas de imitación o falsas, para hacer pasar la pieza por original. Por último, el tercer término hace referencia a la hechura de piezas inspiradas en las características de los estilos históricos, como es propio del XIX, pero sin recrear ninguna pieza existente y a menudo con elementos eclécticos, sin pretensión de hacerlas pasar por originales. CRUZ VALDOVINOS, José Manuel, Platería en la Fundación Lázaro Galdiano, Fundación Lázaro Galdiano, Madrid, 2000, pp. 16-18.

40 Para ampliar sobre la recuperación de este tipo en el siglo XIX, véase: SILVA, Nuno Vassallo e, Ourivesaria Portuguesa... opus cit., pp. 213-243. 
este caso, contamos con dos núcleos principales en los que se copió exactamente la bandeja del Kunsthistorisches.

El primero al que tenemos que referirnos, por su proximidad, es la propia Viena. El obrador de reproducciones galvanoplásticas de Karl Haas $^{41}$, vinculado a la Escuela de Artes Aplicadas de la ciudad -que dio lugar al museo del mismo nombre-, realizó copias en serie de esta bandeja. Uno de ellos se conserva en el propio museo (núm. de inventario: G079) (fig. 3).

El segundo núcleo en el que hemos hallado reproducciones e imitaciones es la Península Ibérica, y esto constituye una cuestión más interesante, porque aunque bien es cierto que la original de Viena fue realizada en Lisboa,

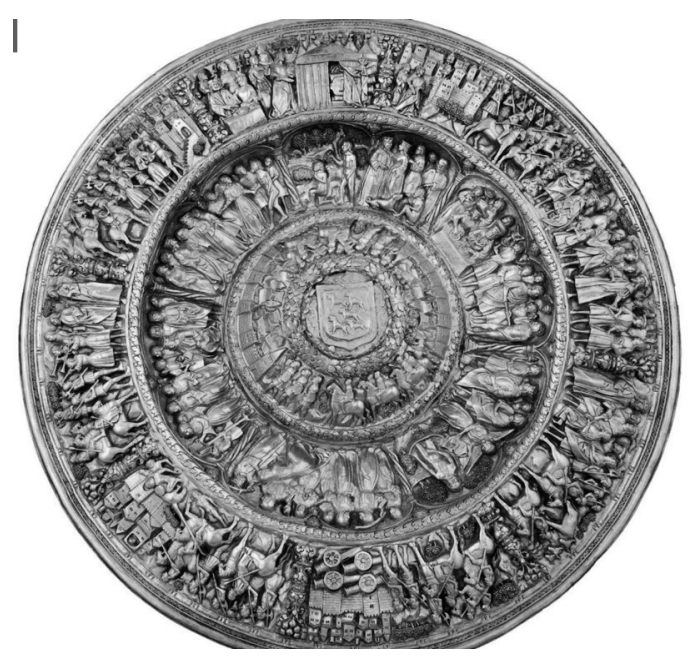

Fig. 3. Karl Haas, Salva de Judit y Holofernes, cobre, galvanoplastia, Museo de Artes Aplicadas, Viena, Núm. Inv. G079, tercer tercio del siglo XIX, fotografía proporcionada por el Museo de Artes Aplicadas de Viena.

41 Karl Haas (Viena, 1825-1880) fue pintor, arqueólogo y orfebre. Estudió en la Academia de Bellas Artes, donde luego se dedicó a reproducir réplicas galvanoplásticas de obras célebres de la historia del arte, estableciendo posteriormente una fábrica en Graz. En 1866 trasladó su compañía a Viena, donde fue director del atelier de galvanoplastia de la Escuela de Artes Aplicadas, produciendo un gran número de réplicas electrotípicas que sirvieron como modelos para la formación de los artesanos y artistas. También formó parte de una fundación en Viena que promovió y protegió el uso del bronce. Su hijo homónimo, Karl Haas (1847-1919) también fue platero y profesor de galvanoplastia en la Escuela de Artes Aplicadas. A pesar de compartir nombre y profesión, la copia que conocemos de la bandeja vienesa es de 1868 y está inequívocamente relacionado con el padre. Queremos agradecer a doña Elisabeth Schmuttermeier, conservadora del departamento de Metales del Museo de Artes Aplicadas de Viena, por proporcionarnos esta información sobre el artista. ¿cómo regresó el modelo tres siglos y medio después?

En 1962 Bouza Brey publicó el catálogo de una exposición sobre platería civil compostelana desde el siglo XVI al XIX ${ }^{42}$. De las apenas doce fotos que incluye la publicación, siete son salvas de tipo portugués propias del siglo XVI, lo que nos habla de que fue un tipo muy de moda en la Compostela de finales del siglo XIX, prolongándose a lo largo del siglo XX y hasta por lo menos los años sesenta, cuando se llevó a cabo la muestra. El primer ejemplar lo vemos en tres piezas casi idénticas que ostentan una franja exterior dividida en una cenefa de triángulos decorada, circunscribiendo un busto de Santiago peregrino ${ }^{43}$. Se trata de un tipo de patrón ornamental también habitual en Portugal $^{44}$.

También lo es el que ostenta el segundo modelo, que presenta una bella columnata toscana que sostiene una arcada entrelazada ojival, imprimiendo a la pieza un sabor entre medieval y renacentista. Conocemos hasta otros seis ejemplares de la misma bandeja, que varían mínimamente los elementos epidérmicos, especialmente el asiento. Cuatro de ellas son obras originales del siglo $\mathrm{XVI}^{45}$, mientras que las otras dos fueron halladas en el archivo personal inédito del artífice compostelano Ricardo Martínez Costoya (1859-1929), que reprodujo

42 BOUZA BREY, Fermín, Platería civil compostelana hasta finales del siglo XIX, Instituto de Estudios Gallegos Padre Sarmiento, Santiago de Compostela, 1962.

43 BOUZA BREY, Fermín, Platería civil... opus cit., pp. 12 y 18.

${ }^{44}$ En el Museo de Arte Antiga de Lisboa se conservan una salva con una decoración triangular muy similar, circunscribiendo la imagen de una carabela (núm. de inventario: 1015 Our).

45 El asiento de la pieza de Bouza Brey presenta un pino entre dos flores, por lo que probablemente perteneciese a la casa de San Martiño Pinario (BOUZA BREY, Fermín, Platería civil... opus cit., p. 7). La segunda copia fue publicada a principios del siglo XX (BALSA DE LA VEGA, Rafael, Orfebrería gallega: notas para su historia, Fototipia de Hauser y Menet, Madrid, 1912, sin p.) y ostenta un original Santiago matamoros. La tercera fue subastada en París por Sotheby's en 2014 (SOTHEBY'S, Clasique/Moderne. Arts Décoratifs du XVIe au XIXe siècle, París, 5 de noviembre de 2014, lote 99, recuperado de: http://www.sothebys.com/en/auctions/ecatalogue/2014/arts-decoratifs-16-19eme-siecle pf1411/lot.99.html?locale=en [15/06/2018]), y presenta también un pino, aunque entre vieiras compostelanas. La cuarta fue publicada por SILVA, Nuno Vassallo e, Ourivesaria Portuguesa... opus cit., p. 100, y su medallón central está ocupado por un adorno vegetal de acanto retorcido. 
la pieza al menos en dos ocasiones, documentándola con una fotografía ${ }^{46}$.

Martínez, platero oficial de la catedral de Santiago, fue uno de los artistas más importantes de Compostela en el tránsito del siglo XIX al $\mathrm{XX}^{47}$. El hecho de que este platero copiase esta bandeja del siglo XVI con la columnata es importante por un motivo. En el catálogo de Bouza Brey aparece otra bandeja del mismo platero que reproduce de manera casi exacta la bandeja del Kunsthistorisches Museum de Vie$\mathrm{na}^{48}$. Lamentablemente, esta pieza se ha perdido, pero ya tendríamos nuestra primera copia en territorio español.

En el Museo Arqueológico Nacional de Madrid se conserva un segundo ejemplar, una imitación de la bandeja lisboeta (fig. 4), que fue atribuida por Cruz Valdovinos a Ricardo Martínez, basándose en la imagen publicada por Bouza Brey ${ }^{49}$.

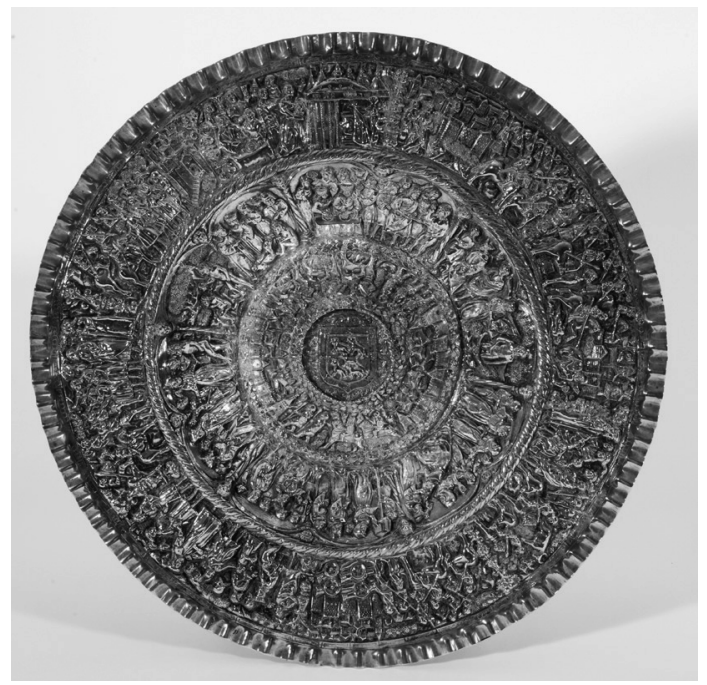

Fig. 4. Ricardo Martínez Costoya, Salva de Judit y Holofernes, plata sobredorada relevada, Museo Arqueológico Nacional, Madrid, Núm. Inv. 59997, ca. 1897, fotografía: Ángel Martínez Levas.

46 Una de ellas fue publicada en: PÉREZ VARELA, Ana, "La platería civil compostelana en el tránsito del siglo XIX al XX a través de las fotografías inéditas del archivo del platero compostelano Ricardo Martínez Costoya”, en Quintana, 18, Santiago de Compostela, 2018, p. 318.

47 PÉREZ VARELA, Ana, "Piezas de Ricardo Martínez Costoya en la colección de platería de la catedral de Santiago de Compostela", en Del taller al museo. Estudios sobre historia del arte, patrimonio y museología en Galicia, Andavira, Santiago de Compostela, 2016, pp. 276-297.

48 BOUZA BREY, Fermín, Platería civil... opus cit., p. 23.

49 CRUZ VALDOVINOS, José Manuel, Catálogo de platería, Museo Arqueológico Nacional, Madrid, pp. 267269.
En la misma década el historiador examinó una bandeja idéntica en colección particular bilbaína que también atribuyó al mismo artista, en la que estaba grabada la fecha de 1897. Por desgracia le hemos perdido la pista a esta copia.

Vasallo y Silva recogió en su investigación estas tres imitaciones compostelanas, siguiendo a Cruz Valdovinos, y señaló ya la importancia de esta salva y su copia en relación con la recuperación decimonónica de modelos del siglo XVI con afán historicista ${ }^{50}$.

Por nuestra parte, aún hemos hallado una cuarta imitación en suelo español, subastada en Madrid por Durán en 2014 (fig. 5), atribuida también a Martínez basándose en Cruz Valdovinos.

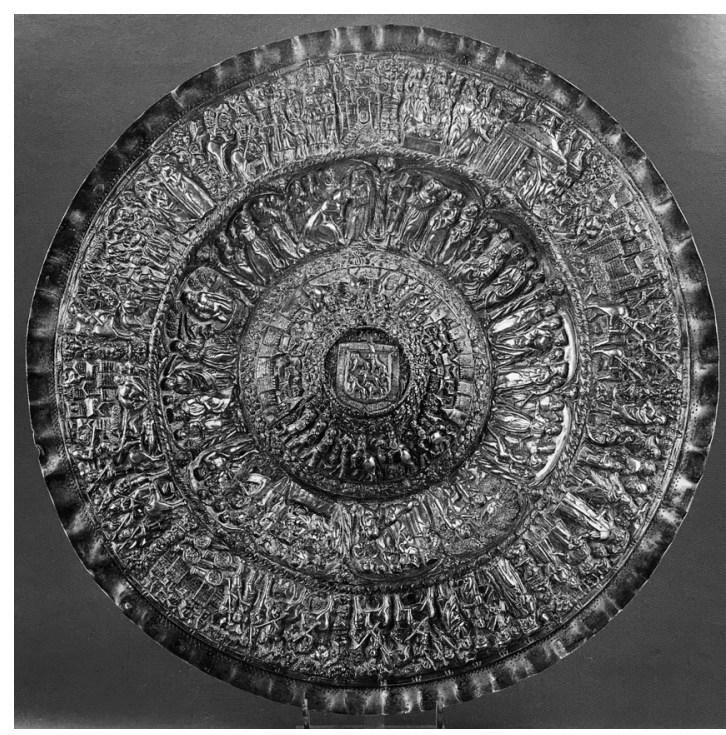

Fig. 5. Ricardo Martínez Costoya, Salva de Judit y Holofernes, plata sobredorada relevada, colección particular, ca. 1897, fotografía proporcionada por Subastas Durán.

Cabría preguntarse si alguna de estas bandejas es la misma. Sólo podrían serlo la publicada por Bouza Brey y la de la colección particular bilbaína, ya que no conservamos ninguna de las dos, y sabemos que la segunda llevaba impresa la fecha, de la que carecen la del Arqueológico Nacional -que además presenta otra disposición escénica- y la de Subastas Durán. A efectos de este estudio las entenderemos como copias separadas, considerando que se conservan cuatro en España.

\footnotetext{
50 SILVA, Nuno Vassallo e, Ourivesaria Portuguesa... opus cit., pp. 222-224.
} 
En el susodicho estudio de Ruival Ferreira, la autora dio a conocer otros cinco ejemplares en territorio portugués. La primera copia se conserva en la Palácio Nacional de Belém. No tenemos más información al respecto que la fotografía aportada en su texto, en la que se indica como una copia hecha en cobre mediante galvanoplastia. No se referencian marcas ${ }^{51}$.

La segunda copia pertenece a la Fundação Dionísio e Alice Cardoso Pinheiro em Águeda, y no presenta marcas. En la colección se catalogó como una pieza del siglo $\mathrm{XVI}^{52}$.

La tercera, una imitación, es en la que se basa para su texto, y fue subastada por la casa lisboeta "Cabral Moncada Leilões" en 2004. Su catálogo la ubicó como parte de la colección del comandante Ernesto Vilhena y posteriormente vendida por la casa "Leiria \&t Nascimento" en 1970. Salió a subasta como una pieza del siglo XVI, cuando ahora tenemos claro que es una copia decimonónica ${ }^{53}$.

La cuarta, también imitación, fue subastada por la misma casa en 2008. Según la información de la venta, presenta marcas falsas de Nüremberg y artífice "IW", ubicándola como obra centroeuropea. Fue a parar a la colección Henrique Braga ${ }^{54}$.

El quinto y último ejemplar en territorio portugués, también imitación, fue vendido por la casa "Leiria \& Nascimento" en 2003. Lamentablemente esta empresa fue disuelta en 2015, con lo que no hemos hallado ninguna información al respecto de esta pieza ni de su paradero actual, aunque la autora del texto apunta a que perteneció a las colecciones Kugel y Alexandre Fernández, lo que ubica la pieza en algún momento en París para llegar luego a Portugal.

La problemática que subyace en estas diez reproducciones/imitaciones es la siguiente: sabemos que Karl Haas copió la bandeja en serie mediante galvanoplastia en el tercer cuarto del siglo XIX en Viena. En España, la única bandeja que podemos relacionar de manera inequívoca con la mano de Ricardo Martínez es la publicada por Bouza Brey ${ }^{55}$, ya que la atribución de

FERREIRA, Sofía Ruival, Salva de... opus cit., sin p.

2 FERREIRA, Sofía Ruival, Salva de... opus cit., sin p.

53 El precio de salida fue de 80.000-120.000 euros. CABRAL MONCADA LEILÕES, Leilão núm. 66, $6^{a}$ sessão, Lisboa, 20 de octubre de 2004, lote 1681.

54 CABRAL MONCADA LEILÕES, Leilão núm. 96, $3^{a}$ sessão, Lisboa, 14-16 de abril, lote 827.

55 Bouza Brey conocía bien la obra de Ricardo Martínez, de quien publicó cuatro piezas en su catálogo (BOUZA las demás piezas en territorio español a Martínez se basa en esa publicación. En cuanto a las bandejas en suelo portugués, ninguna ha sido atribuida. Resulta lógico preguntarse si todos los ejemplos peninsulares -excepto la de Bouza Brey, de la que no dudamos- pueden ser copias vienesas de Karl Haas que llegaron a España.

Realizando una comparación entre estos diez ejemplos podemos extraer conclusiones interesantes, especialmente fijándonos en el tipo de borde. Por una parte, la pieza de Karl Haas (Viena), la de la Fundação Dionísio e Alice Cardoso Pinheiro em Águeda (Portugal) y la del Palácio Nacional de Belém (Portugal) presentan el borde idéntico a la pieza original del Kunsthistorisches: recto y liso, fileteado, adornado con una finísima cenefa de cruces. Este modelo de orilla lisa es el habitual en las salvas portuguesas del siglo $\mathrm{XVI}^{56}$. Se trata por lo tanto de copias o reproducciones sobre un original.

El segundo grupo, formado por las piezas de Bouza Brey, colección bilbaína, Arqueológico Nacional, Subastas Durán -las cuatro en España-, Leira \& Nascimento y las dos de Cabral Moncada Leilões - las tres en Portugal-, ostentan un borde dentado a base de ondulaciones que es una característica propia de las bandejas del siglo XVIII ${ }^{57}$. Es difícil explicar

BREY, Fermín, Platería civil... opus cit., pp. 23-24). En principio no dudamos de su atribución.

56 Podemos verlo en todas las piezas en matriznet citadas en la nota 7; o en las publicadas en: COUTO, João y GONÇALVES, António, A ourivesaria en Portugal, Livros Horizonte, Lisboa, 1970, piezas 70-77; OMAN, Charles, The golden age of Hispanic Silver, Victoria \&t Albert Museum, Londres, 1968, piezas 93-99, 156, 160162, 167-169, 171 y 197; HERNMARCK, Carl, The art of the European Silversmith. 1430-1830, 2 volúmenes, Sotheby Parke Bernet, Londres, 1977, piezas 585-588; SANTOS, Reynaldo dos; y QUILHÓ, Irene, Ourivesaria portuguesa... opus cit., piezas 183, 243, 244, 278, 279, 280, 281, 282, 289; D'OREY, Maria Leonor (dir.). Inventário do... opus cit., piezas 35-39; CRUZ VALDOVINOS, José Manuel, Platería Europea... opus cit., piezas 21, 22 y 49; SOUSA, Gonçalo de Vasconcelos, Pratas portuguesas en colecçoes particulares: séc. VX ao séc. $X X$, Livraria Civilizaçao, Porto, 1998, piezas 1-4 y 6-7; y un gran número de piezas recogidas en SILVA, Nuno Vassallo e, Ourivesaria Portuguesa... opus cit. No hemos hallado en estas publicaciones ni una sola salva historiada del siglo XVI que no lleve este borde. En algunas ocasiones, las menos, aparece festoneado con una crestería.

57 Podemos observarla en varias piezas portuguesas en matriznet, por ejemplo, las identificadas con núms. de inventario 57656; y 18 Our MNSR; así como en las salvas publicadas en COSTA, Laurindo, A ourivesaria e os nossos artistas, Costa \& Cia, Porto, 1917, pp. 41 y 79; COUTO, João y GONÇALVES, António, A ourivesaria... 
que las copias galvanoplásticas de Karl Haas de una pieza del primer renacimiento incorporen un elemento propio del setecientos. Pero en cuanto a la producción de Martínez, no sólo no resulta chocante, sino que es un borde muy característico de algunas de sus piezas ${ }^{58}$. Por supuesto, este recurso ornamental no es exclusivo del platero, pero resulta muy significativo que estas salvas compartan uno de sus tipos de orilla más utilizados ${ }^{59}$, un borde que resulta complicado relacionar con Haas. Se trata por lo tanto no de copias, sino de imitaciones.

Las copias de borde liso reproducen de forma casi idéntica la salva original, gracias a la técnica de la galvanoplastia o electrotipo ${ }^{60}$, que

opus cit., pieza 101; o SANTOS, Reynaldo dos; y QUILHÓ, Irene, Ourivesaria portuguesa... opus cit., pieza 233. Las bandejas ovaladas que presentan ese borde en el siglo XVIII en la península ibérica son innumerables y comunes a todas las regiones.

58 En el catálogo todavía inédito del platero, que incluye más de treinta bandejas, algunas de ellas presentan este tipo de borde. Si ir más lejos, el propio Bouza Brey publicó otro ejemplo que, aunque ostenta un tipo ovalado bien diferente, propia del siglo XVIII, comparte el mismo borde idéntico (BOUZA BREY, Fermín, Platería civil... opus cit., p. 24). Dicho catálogo puede consultarse parcialmente en: PÉREZ VARELA, Ana, Vida $y$ obra del platero compostelano Ricardo Martínez Costoya, Univesidade de Santiago de Compostela [tesis de licenciatura inédita].

59 Con respecto a este elemento, no debemos olvidar que la salva subastada por Cabral Moncada Leilões en 2004 se vendió como una bandeja del siglo XVI, cuando presenta un borde ondulado claramente ecléctico como elemento dieciochesco.

60 La galvanoplastia o electrotipo es una técnica de reproducción de piezas de metal mediante la electricidad, inventado en Rusia por Moritz Jacobi en 1838. La patente fue otorgada en 1840 a los ingleses George y Henry Elkinton, socios de John Wright, que había perfeccionado la galvanoplastia para el oro y la plata. Fueron los fundadores en Birmingham de la industria que se extendería a todo el mundo. En el segundo cuarto del siglo XIX, cuando Karl Haas desarrolla su actividad, era una práctica habitual para copiar en serie piezas de metal. La técnica consiste en aplicar un molde a la obra original -por ejemplo, de cera-, al que se superpone un revestimiento muy fino de polvo de grafito, que actúa como electroconductor. Tras acoplar una serie de alambres a la superficie, el molde es suspendido en un baño con el sulfito de cobre, una pieza de cobre, y carga eléctrica. La carga negativa del grafito atrae los iones del cobre, positivamente cargados, y se forma una fina capa de cobre que puede separarse del molde, resultando en la pieza o la parte de la pieza que se está reproduciendo. Este molde de cobre puede ser reproducido en serie. Mediante una nueva inmersión en un baño de cianuro de plata, con una pieza de plata y carga eléctrica, se consigue el plateado de la pieza de cobre, ya que el mismo procedimiento hace que los iones de plata se adhieran a la superficie. consigue, gracias al vaciado de la pieza en un molde, el traspaso literal de su morfología con todos los detalles. Además, esta técnica permite la reproducción en serie de la pieza. Las posiciones de las tres fajas no coinciden entre las bandejas, ni en el grupo de borde liso, ni en el de borde ondulado. Esto puede deberse a que las piezas se realizaron por secciones, siendo luego ensambladas sin correspondencia idéntica entre las tres fajas y el disco, ya que su disposición no altera la lectura de la historia, ya desordenada de por sí $^{61}$.

En los ejemplos con borde ondulado, las imitaciones, todos los elementos iconográficos se repiten del original. Sin embargo, si las observamos muy detalladamente podemos deducir que las figuras se han realizado mediante relevado o repujado, una técnica manual que dependiendo de la pericia del platero, no consigue reproducir un original de una manera tan idéntica como una copia por electrotipo. Es cierto que la bandeja vendida por Cabral Moncada Leilões en 2004, fue señalada por Ruival Ferreira en su artículo como una copia galvanoplástica. Sin embargo, el catálogo de la subasta no indica la técnica, y según su texto creemos que la autora no tuvo acceso directo a la pieza -sabemos que trabajó con las fotografías proporcionadas por la casa de subastas-, y debió deducir el proceso de manufactura por comparación con la salva del Palácio Nacional de Belém, ejemplar que sí vio. Esta última está catalogada como una copia electrotípica y, no olvidemos, tiene borde liso. Además, no es de plata, sino de cobre. La pieza subastada en 2004 con borde ondulado que pasó por un original del siglo XVI, debió ser entonces de plata relevada.

Aquí tenemos el tercer elemento de comparación: el material. La salva original es de plata sobredorada. Entre las reproducciones de las que hemos podido conocer el material, la de Karl Haas y la del Palácio Nacional de Belém, con borde liso, son de cobre. No tenemos información al respecto de la pieza de la Fundação Dionísio e Alice Cardoso. Al contrario, las seis

\footnotetext{
Dentro de las nueve ejemplos que conocemos - no sabemos en la bilbaína perdida-, resulta interesante recalcar una única excepción con respecto no a la correspondencia de la posición de las fajas, sino a la secuencia de las propias escenas: en la bandeja del Arqueológico Nacional dos de las ocho imágenes de la franja exterior están intercambiadas de sitio. Es una de las copias realizadas a mano mediante relevado.
} 
imitaciones con borde ondulado, son de plata sobredorada. En su carrera, Martínez, trabajó casi en exclusiva con plata -que muchas veces sobredoraba- mediante la técnica del relevado o repujado. No conocemos ninguna pieza suya de cobre ni que emplee técnicas de reproducción en serie.

Estas tres cuestiones: borde, técnica y material, dejan dos grupos diferenciados de obras: reproducciones galvanoplásticas en cobre con borde liso, e imitaciones en plata sobredorada relevadas con borde ondulado. Esto no tiene porqué indicar que cada grupo haya sido realizado por un sólo autor, pero no debemos descartarlo. A la espera de conocer otros posibles autores que copiasen esta pieza, lo más aproximado en estos momentos sería indicar que las piezas del primer grupo podrían pertenecer a Karl Haas, y las piezas del segundo grupo a Ricardo Martínez Costoya. Dentro de esta hipótesis cabe señalar un último dato. Karl Haas murió en 1880, y no debemos olvidar que la bandeja perdida, en colección bilbaína -que sabemos que era de borde ondulado y en plata sobredorada-, ostentaba la marca de 1897 , una época en la que Haas ya había muerto, mientras que Martínez estaba plenamente activo.

Hemos dicho que la existencia en España y Portugal de ejemplos de esta bandeja resulta una cuestión más interesante que los ejemplos vieneses, principalmente por la distancia entre los dos centros. Bien es cierto que la bandeja original era portuguesa, pero como ya hemos indicado, parece que fue enviada a Viena en época contemporánea a su construcción. Resulta lógico pensar que el modelo pudiese volver a Portugal en una época en la que el interés por los historicismos llevó al país a mirar hacia sus piezas diseminadas por toda Europa. Dentro de este pensamiento es fácil tener en cuenta que algún comitente portugués quisiese contar con una copia de Kaal Haas de tal bandeja. A partir de ahí no sería difícil de explicar que llegase a Santiago, debido a la familiaridad entre ambos territorios, que a lo largo de la historia compartieron un flujo de intercambio de influencias estilísticas constante.

Sabemos que Ricardo Martínez estaba familiarizado con este tipo de modelos de salva, que como ya hemos mencionado, fueron habituales en el siglo XVI no sólo en Portugal sino también en Galicia. El platero realizó algunos ejemplos de estas bandejas a los que ya nos hemos referido, como la copia de la salva con la columnata toscana. Además, él mismo realizó un viaje a Portugal en 1982 donde pudo conocer numerosas piezas de este tipo ${ }^{62}$.

El archivo personal del platero estaba formado en gran parte por una serie de recortes y páginas de distintas publicaciones artísticas que circularon en España entre finales del siglo XIX y principios del $\mathrm{XX}^{63}$, lo que indica preocupación y curiosidad por el conocimiento de modelos que bien pudo llevarlo en alguna ocasión a consultar o poseer una publicación que reprodujese esta obra. Sin embargo, el detallismo con el que imitó las piezas demuestra que debió estar en contacto en algún momento con una copia del original. Nos remitimos de nuevo al hecho de que una copia de Karl Haas realizada en el tercer cuarto del siglo XIX pudiese llegar a la Península, ya sea vía Compostela o vía Portugal. Teniendo en cuenta de que en el país luso se conservan hoy en día dos copias galvanoplásticas de borde liso - Palácio Nacional de Belém y la Fundação Dionísio e Alice Cardoso Pinheiro-, que nosotros hemos atribuido a Haas, resulta lógico pensar que ya estuviesen en el siglo XIX, cuando Martínez pudo verlas en su viaje. Recordemos que éste se realiza en 1892, y la única copia fechada es de 1897.

Tenemos conocimiento de que el platero realizó reproducciones e imitaciones de otras obras, tales como la bandeja con la columnata que ya hemos mencionado, o la gran concha realizada para el arzobispo de Mondoñedo en 1906, que reproduce las dos grandes vieiras que Baltasar de Salazar ${ }^{64}$ realizó para la catedral de Santiago entre 1754 y $1760^{65}$. Pese a su esfuerzo

${ }_{62}$ Conocemos este viaje gracias a la prensa. Fue subvencionado por el Ayuntamiento de Santiago junto a otros artistas compostelanos para participar en la Exposición de Industrias Artísticas de Barcelona en 1982. La noticia nos informa de que además de la ciudad condal, decidieron visitar otras ciudades españolas y portuguesas "formando un instructivo itinerario" donde observaron diversidad de obras y patrimonio artístico. Gaceta de Galicia, 23 de septiembre de 1892, p. 3.

63 PÉREZ VARELA, Ana, "La platería civil... opus cit., p. 315.

64 Baltasar de Salazar fue un platero madrileño activo a partir de la década de los veinte del siglo XVIII. Tuvo una actividad muy fecunda, realizando obras tanto sacras como civiles. Fue nombrado platero supernumerario de la Real Cámara en 1736. Murió en 1762. En las bandejas catedralicias emplea la segunda variante de su marca, B. SA / LAZR.

65 Pese a su calidad, apenas existen menciones bibliográficas sobre estas bandejas: FILGUEIRA VALVERDE, José, El Tesoro de la catedral compostelana, Bibliófilos Gallegos, Santiago de Compostela, 1959, p. 81; y BARRAL IGLESIAS, Alejandro, "0 Museo e o tesouro”, 
por imitar las piezas madrileñas, la concha de Martínez no logra reproducir la calidad de las originales $^{66}$. El estilo del platero al realizar las copias tiende a presentar un aspecto más ecléctico y decimonónico, introduciendo pequeñas recetas propias. Es el caso de sus bandejas que copian el original de Viena, que introducen el personal borde ondulado, y algunos mínimos detalles decorativos.

La importancia de Martínez en la Compostela de la época y la gran cantidad de fotografías de piezas civiles que conserva su archivo, nos indica que a su obrador debieron acudir a encargar obras gran cantidad de santiagueses, que seguramente tuvieron a su disposición, además de algunas piezas modelo, las fotografías sacadas por el propio platero que le permitían confeccionar una especie de libro de muestras. El hecho de que en su vasto catálogo se repitan insistentemente algunos tipos - bandejas redondas y ovaladas, platos de orilla decorada $o$ asiento con escenas iconográficas- nos da a entender que fueron piezas muy demandadas por la clientela civil y que el platero empleó unos modelos estructurales similares que variaba especialmente en patrones decorativos y estilísticos, por lo que no es difícil explicar que realizase hasta siete copias de la bandeja portuguesa que tanta demanda pudo alcanzar en la Compostela decimonónica historicista.

No tenemos duda de que debió de ser una pieza de gran ostentación en una época en la que la platería compostelana estuvo protagonizada, de forma general, por las piezas de corte sencillo, sin demasiado adorno. La salva de Judit y Holofernes es una honrosa excepción que sin duda debió ser encargada por familias pudientes e importantes de la ciudad, y que a la vez está muy en relación con el gusto historicista impreso en las artes decorativas demandadas por las élites de la época. Su calidad hizo que, al contrario que la mayoría de piezas decimonónicas de los plateros compostelanos, que se han perdido o fundido, éstas circulasen por las casas de subastas a lo largo del siglo $\mathrm{XX}$ llegando así a las colecciones particulares españolas y portuguesas y al Museo Arqueológico Nacional.

en A Catedral de Santiago de Compostela, Xuntanza, Laracha, 1993, p. 528.

66 Ostenta ces marcadamente neorrococós, y contarios de perlas entre las hojas de acanto, un tipo de adorno propio de los plateros compostelanos del XIX. El dibujo de Martínez es más superficial, ordenado y limpio, mientras que Salazar utiliza más el relieve, y consigue un aspecto general más naturalista y orgánico. 